LIMA, Wanessa Maria de; SARAIVA, Joseana Maria; ALVES, Denice Saraiva de Alencar. Representações sociais das gestoras e profissionais da educação infantil da rede municipal de Recife-PE sobre a qualidade da educação. Oikos: Família e Sociedade em Debate, v. 31, n. 2 , p.383-405, 2020. http://dx.doi.org/10.31423 oikos.v31i2/.9447

\title{
REPRESENTAÇÕES SOCIAIS DAS GESTORAS E PROFISSIONAIS DA EDUCAÇÃO INFANTIL DA REDE MUNICIPAL DE RECIFE-PE SOBRE A QUALIDADE DA EDUCAÇÃO
}

\author{
SOCIAL REPRESENTATIONS OF THE CHILDREN'S MANAGEMENT AND \\ PROFESSIONALS OF THE MUNICIPAL NETWORK OF RECIFE-PE ON THE QUALITY OF \\ EDUCATION
}

\section{REPRESENTACIONES SOCIALES DE GESTORES Y PROFESIONALES DE LA EDUCACIÓN INFANTIL DE LA RED MUNICIPAL DE RECIFE-PE SOBRE LA CUALIDAD DE LA EDUCACIÓN}

\author{
Wanessa Maria de Lima \\ Joseana Maria Saraiva ${ }^{2}$ \\ Denice Saraiva de Alencar Alves ${ }^{3}$
}

\begin{abstract}
Resumo
As instituições de Educação Infantil como meios de consumo coletivo são indispensáveis ao desenvolvimento integral da criança. Contudo, verifica-se um paradoxo entre o avanço na legislação, que garante a efetivação desse direito, e a realidade marcada pela precarização e baixo padrão de qualidade dos serviços prestados. Dessa forma, este estudo tem como objetivo analisar as representações sociais das gestoras e profissionais que atuam na rede de Educação Infantil do município de Recife-PE acerca da qualidade desses serviços. Trata-se de estudo de caso de abordagem qualitativa, cujos resultados apontam como principais entraves a carência de conhecimentos teóricos sobre o tema, bem como o desconhecimento generalizado dos documentos do Ministério da Educação que direcionam as ações dessa modalidade de ensino com ênfase na qualidade da Educação Infantil.
\end{abstract}

Palavras-chave: Educação Infantil. Representações Sociais. Qualidade. Gestores.

\begin{abstract}
Early childhood education institutions as a means of collective consumption are indispensable for the integral development of children. However, there is a paradox between the advance in legislation, which guarantees the realization of this right, and the reality marked by the precariousness and low quality standards of the services provided. Thus, this study aims to analyze the social representations of managers and professionals who work in the Early Childhood Education network in the city of Recife-PE about the quality of these services. This is a case study with a qualitative approach, the results of which point out as the main obstacles the lack of theoretical knowledge on the theme, as well as the general lack of knowledge of the Ministry of Education documents that direct the actions of this teaching modality with an emphasis on quality of Early Childhood Education.
\end{abstract}

Keywords: Social Representations. Quality. Child education. Managers

\footnotetext{
${ }^{1}$ Economista Doméstico. Educador Físico. Pedagoga. Especialista em Gestão Pública/UFRPE, em Educação Infantil / ESAB, em Saúde Coletiva / FUNESO e em Gestão do Trabalho Pedagógico: supervisão, orientação, inspeção e administração escolar / FAVENI. Mestre em Consumo, Cotidiano e Desenvolvimento Social / UFRPE. Membro do Núcleo de Estudos e Pesquisas em Políticas Públicas para Infância e Adolescência/ NEPIAD/UFRPE. Professora de Educação Infantil e do Ensino Fundamental da Prefeitura de Vitória de Santo Antão-PE. wanessaefed@yahoo.com.br https://orcid.org/0000-0002-6069-4548

${ }^{2}$ Economista Doméstico. Especialista em Metodologia da Pesquisa Social/UFC. Mestre em Nutrição Saúde Pública/UFPE. Doutora em Serviço Social/UFPE. Professora do Curso de Graduação em Economia Doméstica e em Ciências de Consumo da UFRPE. Professora do Programa de Pós-graduação em Consumo, Cotidiano e Desenvolvimento Social (PGCDS/ UFRPE). Coordenadora do Núcleo de Estudos e Pesquisa em Políticas Públicas para Infância e Adolescência - NEPIAD / UFRPE. E-mail: joseanasaraiva@yahoo.com.br https://orcid.org/0000-0003-0187-6023

${ }^{3}$ Graduada em Historia /URCA. Graduada em Letras/UFC. Pós-graduada em História da Sociologia. Pósgraduada em Espanhol /UFC. Professora da Escola Técnica Estadual Governador Adauto Bezerra / Crato - CE. https://orcid.org/0000-0002-0842-2772 https://orcid.org/0000-0002-0842-2772
} 


\section{Resumen}

Las instituciones de Educación Infantil como medios de consumo colectivo son indispensables al desarrollo integral del niño. Sin embargo, se verifica un paradojo entre el avanzo en la legislación, que garantiza la realización de ese derecho, y la realidad marcada por la precarización y bajo patrón de cualidad de los servicios prestados. De esa forma, este estudio tiene como objetivo analizar las representaciones sociales de gestores y de profesionales que actúan en la red de Educación Infantil del Ayuntamiento de Recife-PE acerca de la cualidad de esos servicios. Se trata de un estudio de caso de abordaje cualitativa, cuyos resultados apuntan como principales trabas a la carencia de conocimientos teóricos sobre el tema, bien como el desconocimiento generalizado de los documentos del Ministerio de la Educación que direccionan las acciones de esa modalidad de enseñanza con énfasis en la cualidad de la Educación Infantil.

Palabras clave: Representaciones Sociales. Cualidad. Educación Infantil. Gestores.

\section{INTRODUÇÃO}

A produção bibliográfica que trata da Educação Infantil como meio de consumo coletivo enfatiza sua importância como indispensável ao desenvolvimento integral da criança, isto é, físico-motor, cognitivo, afetivo e social.

Segundo Lima (2016, p. 61), o fenômeno consumo coletivo tem despertado o interesse de muitos estudiosos (Castells e Godard, 1974; Lojkine, 1979; Preteceille, 1986; Jaramillo, 1986; Veras, 2000; Roma, 2005; Saraiva, 2009/2015; Dowbor, 2016; Pereira, 2016; Lima, 2016, entre outros) a partir da metade do século XX. A análise desse fenômeno tem centrado a atenção, principalmente, na intervenção do Estado na produção e distribuição dos equipamentos e serviços de consumo coletivo público como valores de uso coletivo, essenciais e indispensáveis ao desenvolvimento econômico e social, bem como à reprodução da força de trabalho e à produção do capital.

Para esses teóricos, compreender esse fenômeno implica entender que a organização do espaço urbano, as infraestruturas, os equipamentos, os produtos e os serviços determinam as condições e a qualidade de vida da população, por meio do consumo, tanto no plano individual quanto no coletivo, no contexto das iniciativas públicas ou privadas, no urbano e no rural.

Segundo Saraiva (2015, p. 35), o consumo individual dirige-se a uma necessidade particular de um indivíduo, dependente do salário auferido (um objeto ou um produto perfeitamente individualizado ou aqueles bens e serviços comprados individualmente alimentos, roupas, móveis, atendimento médico, serviços de beleza, de cuidados, dentre outros). O consumo coletivo diz respeito aos serviços coletivos, que se constituem como valores de uso coletivo indispensáveis ao desenvolvimento econômico e social, bem como à reprodução da força de trabalho e à produção do capital, que só podem ser consumidos de forma coletiva, devido às suas características específicas. A apropriação dos bens (produtos) e 
serviços de consumo coletivo de caráter público é, nas sociedades democráticas, um direito inalienável de todo cidadão, necessário à promoção e à manutenção da educação, saúde, assistência social - creches, pré-escolas, hospitais, centros de saúde, instituições de longa permanência para idosos, parques e outras demandas sociais.

Roma (2005, p. 28) destaca os meios de consumo coletivo como imprescindíveis para a vida na cidade, sobretudo, para os segmentos menos favorecidos, que dependem dos equipamentos e serviços públicos coletivos para satisfazer as suas necessidades. Corroborando Roma, Dowbor (2016, p. 83) é enfático em afirmar que o consumo coletivo é essencial para as populações. Para ele, o consumo coletivo consiste em políticas públicas e sociais como saúde, educação, água, saneamento, transporte coletivo, segurança pública, cultura e afins, fundamentais para o bem-estar e qualidade de vida dos indivíduos, grupos e família. $\mathrm{O}$ autor destaca ainda que o consumo coletivo tem a vantagem de gerar o sentimento de segurança vital, por ser imprescindível para a vida das crianças, dos jovens e também para os adultos e idosos.

No entanto, para Lojkine (1978) uma das contradições das relações de consumo diz respeito à luta pelo acesso a esses bens e serviços sociais caracterizados como consumo coletivo, isto é, educação, saúde, habitação, infraestrutura básica (rodovias, telefonia, saneamento e outros serviços necessários à reprodução da força de trabalho). Tratar esse aspecto, frente à crescente retração do Estado como provedor desses bens e serviços essenciais, torna-se questão fundamental no campo das Ciências Domésticas, Ciências do Consumo e Ciências Sociais.

Especificamente no campo da educação, vários estudos (Vieira, 1988; Hadadd, 1989; Lima, 1990; Silva, 1993; Saraiva, 1999/2015; PNE, 2001; Campos, 2013; Lima e Sariava 2016. entre outros) têm mostrado que, apesar dos grandes avanços na legislação a partir de 1980, observa-se que a rede de serviços de consumo coletivo de atendimento à criança, constituída pelas creches e pré-escolas, muito pouco se tem expandido, enquanto crescem as demandas e as reivindicações por novas medidas de serviço e por uma educação de qualidade. A Educação Infantil, enquanto política social, tem se caracterizado como um apêndice da área de educação e não tem se efetivado como prioridade eleita pelas políticas públicas, sendo a destinação de recursos públicos ainda uma questão não resolvida.

Em razão disso, os governos ao longo da História têm empreendido iniciativas de provimento de valores de uso coletivo e cuidados e educação da criança, mas, na maioria das vezes, não correspondem aos interesses das populações beneficiárias. Ao analisar as 
propostas de implementação da Educação Infantil no País, historicamente, são privilegiados modelos que minimizam os investimentos públicos, que se apoiam nos recursos da comunidade, nos espaços, nos materiais, equipamentos e recursos humanos não qualificados, justificando um atendimento de baixo custo e, por conseguinte, de baixo padrão de qualidade.

Com efeito, a Constituição de 1988 determinou o direito aos cuidados e à educação das crianças de 0 a 6 anos em creches e pré-escolas, bem como o dever do Estado em garantir a sua efetivação como direito de todas as crianças. O conjunto destes direitos, reunidos no Estatuto da Criança e do Adolescente (Lei nº 8.069/1990) e na Lei de Diretrizes e Bases da Educação Nacional - LDB (Lei 9394/96) define a Educação Infantil como primeira etapa da Educação Básica, destinada às crianças de 0 a 6 anos de idade, e deve ser oferecida em creches e pré-escolas, com qualidade, como direito de todas as crianças. Essas instituições devem cumprir duas funções básicas, complementares e indissolúveis: cuidar e educar, complementando os cuidados e a educação realizados pela família (BRASIL, 1996).

Apesar dessa legislação, a situação de precarização dos serviços prestados à criança de 0 a 6 anos persiste. Estudos mostram que a grande maioria das creches e pré-escolas não conta com infraestrutura física adequada nem com profissionais qualificados, não desenvolve programas educativos, não dispõe de mobiliário, brinquedos e outros materiais pedagógicos adequados e indispensáveis ao desenvolvimento integral da criança (PNE, 2001, p.45).

Ciente deste problema e considerando as discussões que vinham sendo realizadas em torno das demandas dos estados e municípios por uma Educação Infantil de qualidade para todas as crianças, independentemente de condição social, em 1995 o Ministério da Educação definiu a melhoria da qualidade do atendimento educacional nas creches e pré-escolas como principal objetivo (BRASIL, 2003, p.9). Em 2005, a Política Nacional de Educação Infantil estabeleceu como um dos seus objetivos principais, a promoção da melhoria da qualidade do atendimento à criança em instituições de Educação Infantil (BRASIL, 2005).

Nesse contexto, o governo federal publicou vários documentos com ênfase na melhoria do padrão de qualidade da Educação Infantil, como estratégia para enfrentar o problema da precarização das políticas de atendimento à criança e do baixo padrão de qualidade das creches e pré-escolas. Entre esses, o Ministério da Educação (MEC) apresentou em 2006 os Parâmetros Nacionais de Qualidade para a Educação Infantil - Volumes 1 e 2 e, em 2009, os Indicadores da Qualidade na Educação Infantil. Estes documentos contêm referências fundamentais para a organização, funcionamento, supervisão, controle e avaliação a serem utilizadas pelas creches, pré-escolas e centros de Educação Infantil, visando à melhoria real da 
qualidade da Educação Infantil para todas as crianças brasileiras de 0 a 6 anos (BRASIL, 2006, p. 4).

Para Zabalza, 1998; Moss, 2002; MEC, 2003; Demo, 2006; Davok, 2007; Campos, 2013; Gentilli, 2015, dentre outros teóricos que discutem sobre a questão, o processo de compreensão da condição qualidade na Educação Infantil é essencial no campo educacional, tendo em vista embasar os estudos e as práticas, bem como os critérios, as dimensões e os fatores que apontam para a construção de uma educação de qualidade, a partir desses documentos. Sem uma compreensão dos gestores e dos profissionais acerca do significado e da importância da qualidade para Educação Infantil, torna-se mais difícil instrumentalizar esses documentos como elementos para melhoria de sua qualidade.

Nessa direção, o recorte que se faz para este estudo compõe as seguintes indagações: os documentos propostos pelo Ministério da Educação - Parâmetros Nacionais de Qualidade para a Educação Infantil (2006) e os Indicadores da Qualidade na Educação Infantil (2009) estão sendo adotados pelas instituições de Educação Infantil, conforme orienta o MEC (BRASIL, 2006)? Ademais, estão sendo utilizados pelas instituições de Educação Infantil como referência para a organização, funcionamento, supervisão, controle e avaliação da Educação Infantil? Sua utilização tem resultado em melhoria da qualidade real da Educação Infantil, no âmbito das instituições de Educação Infantil? Mais especificamente, este estudo centra sua atenção na seguinte indagação: os gestores e os profissionais das instituições de Educação Infantil, sujeitos da pesquisa, compreendem o significado da qualidade para a Educação Infantil proposta pelo MEC?

O primeiro tópico ocupa-se em mostrar a problemática e a delimitação dos objetivos da pesquisa, considerando a abordagem das instituições de Educação Infantil como meio de consumo coletivo, os documentos intitulados Parâmetros Nacionais de Qualidade para a Educação Infantil e os Indicadores da Qualidade para Educação Infantil, instrumentos e objeto de estudo efetivo para análise e discussão dos resultados da investigação que se propõe realizar.

O segundo item trata dos procedimentos metodológicos, incluindo a natureza do estudo, o tipo de abordagem, o universo e a amostra, o instrumento de coleta de dados e o método de análise utilizado para a discussão dos resultados.

O terceiro item aborda os resultados e a discussão da análise das representações sociais dos gestores, coordenadoras pedagógicas, professoras e auxiliares de Educação 
Infantil, envolvidos com a Política de Educação Infantil municipal sobre qualidade da educação e seus desdobramentos para melhoria da qualidade da Educação Infantil.

O quarto item, a partir dos resultados, pretende agregar conhecimentos, estimular novas reflexões, proporcionar a troca de ideias acerca dos diferentes discursos que têm fundamentado o debate sobre a qualidade da Educação Infantil. Nessa direção, visa contribuir para o desenvolvimento e fortalecimento da Política Nacional de Educação Infantil frente à efetivação do direito da criança à educação pública de qualidade socialmente referenciada.

\section{PROCEDIMENTOS METODOLÓGICOS}

Adotou-se a abordagem Qualitativa e o Estudo de Caso como ferramentas para compreender o fenômeno investigado. A opção por este tipo de estudo justifica-se por se tratar o objeto de estudo de um fenômeno social contemporâneo, através do qual se apreendeu 0 seu contexto real de forma ampla, abrangente e detalhada, e um relato ordenado e crítico da experiência, tendo em vista propor uma ação transformadora. Ademais, essa tipologia de estudo propiciou a utilização de métodos e técnicas diversificadas - documentos, entrevistas, relatos, avaliações - de modo a explorar o potencial descritivo e explicativo do fenômeno social de forma ampla e crítica. Segundo Yin (2001, p, 23), o Estudo de Caso contribui para compreender os fenômenos sociais, organizacionais e políticos da sociedade contemporânea de forma ampla e concreta.

Optou-se por trabalhar com instituições de Educação Infantil mantidas pelo poder público em função da maior vulnerabilidade social de sua clientela, das condições de precarização de funcionamento apresentadas pela literatura e da grande representatividade demográfica da população que atendem. Em 2015, segundo dados da Prefeitura do Recife, local onde se realizou a pesquisa, considerando creches e Centros Municipais de Educação Infantil (CMEls) totalizavam-se 69 unidades. Conforme o Plano Plurianual (2014-2017) e de acordo com a relação de Creches e Pré-escolas e CMEls da Rede Municipal da Prefeitura do Recife (Secretaria de Educação, 2016 s/p), existia à época na rede 800 professores, 73 gestores e coordenadores pedagógicos de creches, pré-escolas e CMEls e 680 auxiliares de Educação Infantil (ADIs) distribuídos em atividade na rede (PREFEITURA MUNICIPAL DE RECIFE, 2015, p.1)

Participaram da pesquisa 36 profissionais (gestor, coordenador pedagógico, professor e auxiliar de desenvolvimento infantil) ligados a um Centro Municipal de Educação Infantil e 
creche/pré-escola de cada uma das seis Regiões Político-Administrativas - RPA's RPA de Recife, totalizando 12 equipamentos de consumo coletivo. Sendo 6 CMEls e 6 creches e préescolas.

A fim de compreender as interpretações, ideias, visões e concepções que os gestores públicos, professores e auxiliares de Educação Infantil possuem a respeito da problemática em questão, insere-se neste estudo o conceito das representações sociais, que tem como figura central Serge Moscovici, o qual defende que as representações sociais se constituem uma teoria e uma das formas de compreensão da realidade, do mundo concreto, permitindo encontrar elementos do discurso social trazido pelos sujeitos sociais (MOSCOVICI, 2003, p. 29). Conforme Alvântara e Vesce (2008, p. 211), as representações sociais consistem em um campo de conhecimento específico que tem por funções a construção de condutas comportamentais e o estabelecimento de comunicação entre sujeitos em um grupo social produtor de interações interpessoais.

Segundo Siqueira (2008, p. 20), Moscovici denominou representação social aquilo a que ele chamou de Teorias do Senso Comum, ou seja, a ideia de que os indivíduos constroem no cotidiano teorias a respeito dos objetos sociais, as quais são orientadoras dos comportamentos dos seres humanos. Nesse sentido, buscava compreender o processo de construção de teorias do senso comum, mostrando que este se diferencia dos outros tipos de conhecimento. Segundo Gramsci (1989), o senso comum seria o ponto inicial de onde se deveria partir para construir uma nova concepção de mundo, uma consciência crítica, possibilidade de gerar mudanças, de ser capaz de se transpor de uma consciência ingênua do mundo para uma consciência crítica.

Neste sentido, este estudo vale-se da Teoria das Representações Sociais a fim de compreender as interpretações, visões, concepções, valores, opiniões e ideias que os gestores, coordenadores pedagógicos, professores e auxiliares de Educação Infantil possuem a respeito da problemática em questão.

A entrevista estruturada foi utilizada como técnica principal de coleta de dados, por ser a mais adequada para a obtenção do contexto social estudado. Segundo Richardson (2009, p. 207), ela é um importante técnica, que permite o desenvolvimento de estreita relação entre o entrevistador e o sujeito entrevistado, facilitando a interação face à face, elemento fundamental na pesquisa em ciências sociais.

Considerando essa perspectiva, elaborou-se um formulário de entrevista composto com perguntas abertas e fechadas, que subsidiou o processo de investigação. A primeira versão do 
formulário de entrevista foi pré-testada com um sujeito de cada categoria profissional, entre aqueles não selecionados para integrar a amostra, tendo-se verificado a sua adequação no que concerne à extensão e à compreensão das perguntas, bem como à pertinência das questões aos propósitos do estudo. As entrevistas foram realizadas pela própria autora, gravadas e registradas. No final, cada sujeito ciente da entrevista assinava o Termo de Consentimento Livre Esclarecido.

As representações sociais de cunho qualitativo foram tabuladas e, posteriormente, categorizadas e agrupadas segundo o teor/conteúdo das respostas, destacando os depoimentos mais significativos dos entrevistados e apresentados em forma de tabela, sobressaindo às frequências estatísticas. As respostas foram analisadas em seguida, tendo como referência a teoria das representações sociais.

No que concerne à questão ética da pesquisa, o estudo não possui obrigatoriedade do Parecer do Comitê de Ética, por se tratar de um estudo de abordagem qualitativa, não envolvendo aspectos clínicos, epidemiológicos ou experimentação com seres humanos.

\section{O QUE PENSAM OS SUJEITOS DA PESQUISA ACERCA DA QUALIDADE DA EDUCAÇÃO}

A partir das representações sociais dos sujeitos da pesquisa, mediante o uso das linguagens oral e escrita, apreendeu-se o que os sujeitos pensam, como percebem e que expectativas desenvolvem a respeito da qualidade da Educação Infantil.

TABELA 1 - Representações sociais das gestoras, coordenadoras pedagógicas, professoras e auxiliares de instituições de Educação Infantil acerca da qualidade da educação, o debate sobre qualidade da educação e os aspectos/fatores considerados para promoção da qualidade da educação - Recife, 2016.

\section{Frequência das Respostas}

\section{Representações Sociais}

\begin{tabular}{cccc}
\hline \multicolumn{2}{c}{ Gestoras e Coord. Pedg } & $\begin{array}{c}\text { Professoras e } \\
\text { ADI }\end{array}$ \\
\hline $\mathbf{N}$ & $\%$ & $\mathbf{N}$ & $\%$ \\
\hline
\end{tabular}

\section{O que entende sobre qualidade da educação?}

É aquela que é boa (que tem eficiência, excelência, eficácia, funciona perfeitamente);

Envolve estrutura física, material e pessoal qualificado;

É aquela que oferece alimentação, saúde, bem-estar para as crianças;

É mostrar um bom serviço (bom atendimento);

Não sabe responder;

TOTAL

$\begin{array}{cccc}5 & 35,71 & 9 & 32,14 \\ 3 & 21,42 & 4 & 14,28 \\ 3 & 21,42 & 7 & 25,00 \\ 1 & 7,14 & 3 & 10.71 \\ 2 & 14,28 & 5 & 17,85 \\ \mathbf{1 4} & \mathbf{1 0 0 , 0} & \mathbf{2 8} & \mathbf{1 0 0 , 0}\end{array}$




\section{Como avalia o debate sobre a qualidade da educação?}

Existe na teoria, mas, não existe na prática (é utopia);

Não sabe responder;

Só existe no debate (se fala muito, mas, nada acontece);

O debate sobre qualidade existe, mas, está longe de ser cumprido.

TOTAL

\author{
de ser
}

$\begin{array}{lrrc}6 & 50,00 & 9 & 37,50 \\ 5 & 41,66 & 7 & 29,16 \\ 1 & 8,33 & 4 & 16,66 \\ 1 & 8,33 & 4 & 16,66\end{array}$

12

100,0

24

100,0

Que dimensões (aspectos/fatores) devem ser consideradas para a promoção efetiva da qualidade da educação?

\begin{tabular}{|c|c|c|c|c|}
\hline $\begin{array}{l}\text { Infraestrutura física e material (salas maiores; brinquedos; jogos; } \\
\text { materiais didáticos); }\end{array}$ & 8 & 34,78 & 19 & 44,18 \\
\hline $\begin{array}{l}\text { Formação profissional (das professoras, ADIs, coordenadoras, } \\
\text { estagiárias); }\end{array}$ & 6 & 26,08 & 10 & 23,25 \\
\hline $\begin{array}{l}\text { Condições dignas de trabalho (salário digno; formação; redução } \\
\text { de carga horária; materiais de trabalho); }\end{array}$ & 3 & 13,04 & 3 & 13,03 \\
\hline $\begin{array}{l}\text { Aspectos socioafetivos (relação família/escola; relações } \\
\text { humanas/ comunicação); }\end{array}$ & 1 & 4,34 & 1 & 4,34 \\
\hline Suporte aos alunos (assistência; alimentação; saúde; educação); & 5 & 21,73 & 10 & 23,25 \\
\hline & 23 & 100,0 & 43 & 100,0 \\
\hline
\end{tabular}

Fonte: Dados das autoras

Os resultados refletem a multidimensionalidade que o termo qualidade na educação apresenta a partir de diferentes perspectivas e critérios relacionados aos valores, crenças, visões, concepções e experiências que os sujeitos envolvidos com a Educação Infantil possuem. Os resultados revelam que a maioria dos sujeitos $(67,85)$ envolvidos com a Educação Infantil centra o discurso da qualidade da educação na importância dos aspectos técnicos, de produção e de eficiência da qualidade. Esta preocupação pode ser observada na fala das entrevistadas, a partir das representações transcritas.

É algo relacionado a algo que é bom, eficiente que é produtivo (Coordenadora
Pedagógica);
É aquela que faz coisas seguindo os preceitos certos, da eficiência (Auxiliar de
Desenvolvimento Infantil);
É aquela que dá o máximo para que saia tudo como se quer, bem-feita, com eficiência,
com resultados esperados (Gestora);
É algo que é excelente no atendimento (Coordenadora Pedagógica).
sobre qualidade da educação para a maioria dos sujeitos, conforme O discurso sobre qualidade da educação para a maioria dos sujeitos, conforme
m os depoimentos, reflete uma visão ainda limitada e estritamente técnica, baseada em mostram os depoimentos, reflete uma visão ainda limitada e estritamente técnica, baseada em princípios de eficiência. Remete a conceitos e significados de qualidade, cujo enfoque reproduz a abordagem da qualidade defendida pelo sistema produtivo empresarial, enraizada nas teorias tecnicistas, mecanicistas e funcionalistas da teoria Taylorista do início do século passado, ou 
seja, limitada e estritamente técnica, baseada em princípios gerenciais cujos resultados finais da quantidade produtiva é o que interessa.

Estudos mais recentes, no campo específico da educação, têm contribuído para superação conceitual do termo qualidade nessa perspectiva. Para além do âmbito técnico (da excelência e da eficácia), o conceito de qualidade deve ser pensado, principalmente, quando se toma o eixo da qualidade para educação, uma prática administrativa democrática, comprometida com a transformação social e com a melhoria da qualidade da educação. Nesse sentido, segundo Cortella (2007, p. 9), qualidade em educação é um conceito historicamente construído e em disputa, mas cabe aos sujeitos políticos que atuam pelo direito à educação de qualidade especificar quais concepções almejam defender. Tornar a qualidade uma perspectiva democrática, legítima a todos, comprometida com a garantia do direito à educação com qualidade para todos é o grande desafio da educação e dos educadores.

Lima (2016, p. 49), corroborando Cortella (2007, p. 9) acerca da construção histórica do conceito de qualidade em educação, reforça que na antiguidade, Aristóteles tratava desse fenômeno dando ênfase à primeira ideia de escola de Estado como meio de consumo coletivo, preocupado com o bem comum das polis (cidade-Estado). Para esse filósofo, a educação deveria ser pública e de qualidade, um serviço coletivo, a cargo do Estado e igual para todos os cidadãos.

A literatura acerca dos estudos sobre qualidade da educação (Cortella, 2007; Carreira e Pinto, 2007; Lima e Saraiva, 2017) demonstram que os educadores estão impregnados pelo ideário da campanha nacional pelo direito à educação com qualidade. Contudo, o discurso sobre a qualidade da educação para a maioria dos profissionais da Educação Infantil participantes deste estudo restringe-se a significados mais estritamente técnicos e burocráticos. Segundo Carreira e Pinto (2007, p.21), este discurso caracteriza os debates sobre qualidade predominantes na década de 1990, incorporado à agenda da reforma educativa caracterizada como neoliberal. Reforma que foi influenciada pelas agências multilaterais - Banco Mundial, Unesco e ONU - no controle das políticas sociais e de privatização da educação. Nesse período, a qualidade passou a ser vista como mera busca de eficiência, lema da área empresarial que penetra no campo educacional, cuja preocupação com a qualidade se fundamentava na eficiência visando resultados quantitativos.

Contrapondo-se a esta perspectiva, o discurso da qualidade da educação numa perspectiva democrática defende a qualidade como uma condição para todos e não para poucos. Pensar a qualidade nessa perspectiva, significa compreender as desigualdades 
sociais, o compromisso com a inclusão cultural e social, o respeito à diversidade, a sustentabilidade, a democracia e, sobretudo, a universalidade do direito à educação com qualidade. Este novo paradigma, progressivamente, foi sendo transportado para o campo da Educação Infantil, cujo arcabouço teórico evidencia novos padrões de consumo coletivo, sobretudo, em se tratando dos conhecimentos, práticas, e como um discurso oficial para as políticas públicas e sociais.

Numa outra perspectiva, o conceito de qualidade da educação não deve passar apenas pela definição de insumos, do ponto de vista de custos e de garantia de infraestrutura e equipamentos adequados, mas, também, pela qualificação dos profissionais da educação, pelas condições de trabalho satisfatórias e bons salários, componentes indispensáveis para efetivação dos processos de ensino-aprendizagem e garantia de uma escola de qualidade para a maioria, e não para uma minoria privilegiada. Conforme mostram os depoimentos de duas gestoras:

A qualidade na educação envolve três aspectos importantes: infraestrutura física e material, formação adequada de professores e salário dignos;

Ter recurso no ambiente físico, ter profissionais qualificados, bons salários, formação para as ADIs e as estagiárias - não como as que se fornece que não tem utilidade.

Esse discurso reflete, mais especificamente, aquele que brota com a Campanha Nacional pelo Direito à Educação impulsionada por um conjunto de organizações da sociedade civil, no contexto preparatório do processo para a Cúpula Mundial de Educação, realizada em Dacar, no Senegal, em 2000. Segundo Carreira e Pinto (2007, p. 73), a articulação surge com o desafio de somar diferentes forças políticas pela efetivação dos direitos educacionais garantidos por lei, que determina que todos os cidadãos tenham acesso à educação pública de qualidade. Nessa direção, a Campanha visa disseminar amplamente o conceito de educação enquanto direito social, com foco central na qualidade, sobretudo, no financiamento e na valorização e qualificação de seus profissionais.

Nessa perspectiva, a Declaração de Incheon (2015, p. 2) compromete-se com a garantia da promoção de uma educação de qualidade para todos. Ademais, garante que gestores, professores e educadores sejam empoderados, recrutados adequadamente, bem treinados, qualificados profissionalmente, motivados e apoiados em sistemas que disponham de bons recursos e sejam eficientes e dirigidos de maneira eficaz.

Outro discurso acerca da qualidade da educação apreendido a partir das falas de 46,42\% dos profissionais da Educação Infantil - gestores, professores e auxiliares corresponde à percepção da qualidade na educação com foco na higiene, alimentação, saúde e bem-estar das crianças, conforme mostram os depoimentos transcritos abaixo: 
É poder atender as crianças em suas necessidades da melhor forma possível, dá carinho, amor, proteção, alimentação, saúde (Professora);

Suprir tudo que as crianças não têm, comida, afeto, saúde, pois são filhos de drogados (Auxiliar de Desenvolvimento Infantil).

Verifica-se, no conjunto dessas representações sociais, uma concepção de qualidade da educação como condição que vai proteger, e de creche e pré-escola como lugares onde se assiste, alimenta, cuida da saúde e guarda a criança pobre. Observa-se, ainda, o entendimento de qualidade da educação como tendo o objetivo de suprir tudo o que as crianças não têm, sustentado pela visão assistencialista compensatória que possuem sobre estas instituições,com base nos princípios da educação compensatória, considerando a criança pobre sempre em falta, e a creche como compensadora de deficiências biopsicossociais e culturais.

Não se pode deixar de reconhecer na análise que, espaços antes vistos apenas como lugar de guarda e assistência a crianças pobres, com a Constituição (1988) e a LDB (1996), passaram à condição de espaços sociais e educacionais legítimos a toda criança, independentemente de condição social. Entretanto, o que se constata neste estudo, a partir das representações sociais de um percentual considerável das gestoras e das educadoras destas instituições, é que para estas instituições atenderem a estes objetivos de cuidados e educação da criança, no sentido de prestar um atendimento com qualidade, vários aspectos precisam ser reavaliados. Um desses é o rompimento com as concepções assistencialistas que ainda fundamentam o modo como uma parcela das gestoras, responsáveis diretas pela organização e funcionamento das creches e pré-escolas, bem como as professoras e ADIs, as concebem.

\section{COMO OS SUJEITOS AVALIAM O DEBATE SOBRE QUALIDADE DA EDUCAÇÃO}

Nessa direção, os resultados da Tabela 1 revelam que a maioria $(87,50 \%)$ das respostas centra-se na afirmativa de que o debate sobre a qualidade da educação "Existe na teoria, mas, não existe na prática (é utopia) ". Observa-se que as outras respostas, embora com outras palavras, têm significados semelhantes às primeiras representações. Os profissionais das instituições de Educação Infantil têm representações sobre os diferentes percursos seguidos pelo debate da qualidade na educação no Brasil que parecem estar associadas, diretamente, a não efetivação das diretrizes legais que apontam para a melhoria da qualidade do atendimento à criança nessas instituições. Conforme destacam as entrevistadas: 
Eu vejo que falam muito em qualidade, mas, não se pratica, não vemos nada de qualidade, só descaso com a educação infantil (Auxiliar de Desenvolvimento Infantil);

Qualidade? Está só no discurso, nas leis, mas, não se cumpre (Auxiliar de Desenvolvimento Infantil);

A gente vê que é muito posto, educação de qualidade, saúde de qualidade, mas, na realidade só está no nome. Falta muito para se ter uma educação de qualidade. Está na teoria, no debate que é feito nas instituições públicas, mas, só funciona nas intuições privadas, nas públicas se perde no meio do caminho (Coordenadora pedagógica);

Tem muito discurso bonito sobre qualidade. A Constituição veio a melhorar no discurso, mas, na prática não (Professora);

É algo que realmente que precisa ser debatido. Os gestores nem sempre estão preparados. Teoricamente funciona, na prática do dia a dia é diferente. Os gestores não são qualificados (Professora);

Há que se considerar ainda que estas representações refletem o próprio debate do contexto histórico das creches e pré-escolas no Brasil, fundado ao longo do tempo na luta dos movimentos sociais por equipamentos e serviços de consumo coletivos de atendimento à criança, público e de qualidade. Como bem falam as protagonistas da educação infantil, meios de consumo coletivos tantas vezes garantidos na legislação e não efetivados, constatados pela ausência ou pelas limitações de oferta, condições estruturais, materiais e humanas deficientes no atendimento público às crianças.

Contrariando essa condição, para Dowbor (2016, p. 83) os meios de consumo coletivo são essenciais para as populações. Para ele, o consumo coletivo consiste em políticas sociais como saúde, educação, água, saneamento, transporte coletivo, segurança púbica, cultura e afins, fundamentais para o bem-estar e qualidade de vida dos indivíduos, grupos e família. $\mathrm{O}$ autor destaca ainda que os meios de consumo coletivo são imprescindíveis para a vida das crianças, sobremodo, em se tratando das instituições de Educação Infantil como espaços sociais e educacionais legítimos a todas às crianças e como condições necessárias ao processo de produção do capital e de reprodução da força de trabalho, auxiliares necessários do ponto de vista social e econômico (SARAIVA, 2016, p.160)

É importante reconhecer, segundo Campos, Fullgraf e Wiggers (2006, p. 87), que as diretrizes legais que apontam para melhoria da qualidade do atendimento à criança nas instituições de Educação Infantil não puderam ser traduzidas em efetivas medidas práticas. Segundo estas autoras, a distância entre a legislação e a realidade continua, infelizmente, a caracterizar a grande parte da Educação Infantil do País. O avanço do debate sobre qualidade da Educação Infantil que resultou na construção de novas concepções centradas no desenvolvimento da criança, integrando outros aspectos além das demandas físicas, e numa perspectiva democrática comprometida com as transformações sociais e com a melhoria da 
qualidade da educação para todos, não significou mudanças efetivas nas políticas educacionais.

As respostas das entrevistadas são, portanto, compreensíveis, na medida em que reflete a realidade vivenciada pela maioria das instituições de Educação Infantil no Brasil, inclusive de Recife, local onde se realizou este estudo. Pesquisa realizada pelo MEC no ano de 2010, em várias capitais do País e abrangendo 150 Centros de Educação Infantil - financiada pelo Banco Interamericano de Desenvolvimento - comprova esta realidade. O estudo visou avaliar a qualidade da Educação Infantil e evidenciou que as instituições apresentaram níveis de qualidade insatisfatórios nos diferentes aspectos investigados (CAMPOS, 2013, p. 36).

Segundo os resultados desse estudo, foram as rotinas de cuidados pessoais (da saúde, segurança e bem-estar das crianças) que obtiveram as médias mais baixas, correspondendo ao nível de qualidade inadequado. Os espaços e mobiliários (estado de conservação, níveis de conforto, grau de segurança, adequação do ambiente e dos equipamentos destinados a estimular a aprendizagem da criança, a autonomia e o desenvolvimento) apresentaram níveis mínimos de qualidade, ou seja, básicos. Os itens refeição/merenda, sono e prática de saúde obtiveram também níveis de qualidade insatisfatórios, correspondentes ao inadequado. Os materiais disponíveis para as atividades com as crianças (livros, jogos, gravuras, entre outros) e as condições dos espaços onde se desenvolvem as atividades, obtiveram médias muito baixas e preocupantes. Somando-se a isso, os aspectos importantes relativos à programação das atividades estão sendo negligenciados na maioria das instituições avaliadas (CAMPOS et al., 2011, s/p).

Os resultados, além de refletirem a deficiência de conhecimento sobre o assunto em pauta, revelam a desinformação em relação à tendência que a qualidade da educação vem apresentando nas últimas décadas, sobremodo, na perspectiva da Educação Infantil. Para os estudiosos do tema, é fundamental compreender como os diversos discursos do debate sobre a qualidade da educação associados à Educação Infantil estão evoluindo no tempo e no espaço. A compreensão crítica dos diferentes percursos seguidos pelo debate tradicional enraizados nas teorias tecnicistas, mecanicistas e funcionalistas e o debate atual fundado nas novas abordagens - centradas nas estratégias democráticas, comprometidas com a promoção efetiva da qualidade da educação como direito de todos e para todos - vai possibilitar entender o porquê das limitações, conflitos e contradições da efetivação do direito à educação com qualidade. 


\section{ASPECTOS QUE OS GESTORES E PROFISSIONAIS CONSIDERAM PARA A PROMOÇÃO EFETIVA DA QUALIDADE DA EDUCAÇÃO}

Os dados da Tabela 1 relativos a essa pergunta mostram um número de respostas maior do que o número de entrevistados, por terem estes considerado mais de um aspecto/fator importante para a promoção da qualidade da educação. Para 78,96\% das entrevistadas1, a infraestrutura física e material - salas pequenas, falta de material didático, livros, jogos, brinquedos, legos - são aspectos/fatores considerados mais importantes. Em seguida, 49,33\% consideram importante a formação profissional (das professoras, ADIs, coordenadoras, estagiárias). Suporte aos alunos (assistência, alimentação, saúde, moradia) aparece na sequência como terceiro item mais considerado para 40,64\%, tendo em vista a promoção efetiva da qualidade da educação. Os aspectos socioafetivos (relação família/escola; relações humanas/comunicação) e condições dignas de trabalho (salário digno, formação, redução de carga horária, materiais de trabalho) aparecem na sequência, em quarto e quinto lugares, respectivamente, com percentuais quase equivalentes.

Verifica-se que há concordância entre os aspectos/fatores mencionados como os mais importantes - estrutura física e material, seguidos de pessoal qualificado, alimentação, saúde e a concepção que possuem sobre qualidade da educação.

O documento Indicadores da Qualidade na Educação Infantil, publicado pelo MEC (2009, p. 29), apresenta sete dimensões (aspectos/fatores) de qualidade que devem ser utilizadas para avaliação da qualidade das instituições de Educação Infantil: planejamento institucional; multiplicidade de experiências e linguagem; interações; promoção da saúde; espaços, materiais e mobiliários; formação e condições de trabalho para professores e demais profissionais; cooperação e troca com as famílias e participação na rede de proteção.

Embora as entrevistadas apresentem aspectos/fatores que são considerados fundamentais, tendo em vista a promoção da qualidade da educação, verifica-se que cada uma menciona apenas um aspecto ou, no máximo, dois ou três, sendo que nenhuma delas apresenta todos os aspectos/fatores no seu conjunto, como parte integrante de um todo. É importante ressaltar que embora as dimensões recomendadas pelo MEC (2009) se apresentem no documento de forma separada, por uma questão metodológica, o entendimento é que todas as dimensões se constituem como parte integrante de um todo. Isto implica reconhecer que estas dimensões de qualidade na prática devem funcionar de forma articulada, 
uma dependendo da outra no processo educativo, de forma a se atingirem os objetivos da Educação Infantil.

Ao se desvendarem as representações dos sujeitos sobre essas dimensões constata-se o não reconhecimento dessas dimensões como parte de um todo, revelando uma visão fragmentada, não contextualizada, um pensar desarticulado. $O$ escasso ou nenhum conhecimento dessas dimensões, com base nos documentos elaborados pelos órgãos oficiais e pela literatura que trata do assunto é nítido. Essas dimensões compõem os Indicadores da Qualidade para Educação Infantil, documento elaborado e publicado pelo MEC em 2009. São instrumentos que as instituições devem usar para avaliar, com a participação de todos os segmentos que compõem a Educação Infantil e, juntamente com a comunidade, a qualidade do atendimento prestado à criança em seus diversos aspectos - considerando as referidas dimensões - e assim, a partir dos problemas detectados coletivamente, buscar soluções tendo em vista melhorias das práticas pedagógicas e educativas, numa perspectiva participativa e democrática.

Nessa direção, o MEC (2009, p.36) orienta que a apreensão dessas dimensões no seu conjunto, pelos profissionais da Educação Infantil e pela comunidade, é fundamental para a garantia e efetivação da qualidade da Educação Infantil numa perspectiva democrática, legítima a todos, comprometida com a garantia do direito à educação com qualidade para todos, e não para poucos.

A formação para professores e demais profissionais foi a segunda dimensão mais citada pelas entrevistadas, sendo inclusive recorrente no discurso das gestoras e das outras profissionais. Apresenta-se como um dos maiores desafios a ser enfrentado pela Educação Infantil, conforme revelam as entrevistadas:

Você deve eleger um conjunto de três pilares, qualidade dos professores em relação à formação, salário e infraestrutura física, esses pilares são fundamentais (Gestora);

Se não tiver uma política de organização dos profissionais capacitados, com compromisso com o que faz, nada acontece, a qualidade fica só falar (Coordenadora Pedagógica);

Formação continuada mais constante, pois faz tempo que a gente não tem capacitação nenhuma, a gente fica por fora de tudo, não se atualiza, só dão palestra no inicio do período letivo (Professora);

Professores capacitados, material de trabalho e formação adequada para atuar na Educação Infantil, pois tem profissional aqui que são de química e física e atuam na Educação Infantil (professora);

Formação, pelo menos mínima, que a pessoa tenha o mínimo de conhecimento para atuar na Educação Infantil e materiais para utilizar nas atividades com as crianças (Professora). 
Com base nesses depoimentos, é clara a preocupação das entrevistadas em chamar atenção para a relação entre a boa formação dos profissionais e o melhor desempenho das crianças na Educação Infantil e a obtenção da qualidade. Parte-se do princípio de que instituições de Educação Infantil de boa qualidade possuem quadros de profissionais qualificados, com formação inicial e continuada adequada na área de Educação Infantil, com conhecimentos teóricos metodológicos consolidados acerca do cuidar e do educar, sobretudo, comprometidos com a aprendizagem dos seus alunos. A qualificação ou a capacitação, como transmitem as entrevistadas, do professor ou de outros profissionais que trabalham com os cuidados e educação das crianças, é vista como importante aspecto/fator no processo de desenvolvimento integral e na efetivação do desempenho das crianças e, consequentemente, na garantia de uma educação de qualidade.

Campos, Fullgraf e Wiggers (2006, p. 118), com base em pesquisa de revisão de estudos empíricos sobre qualidade da educação em instituições de Educação Infantil, afirmam que os desafios encontrados em relação à formação de professores da Educação Infantil são muitos. De fato, ainda existem muitos educadores sem a formação e a escolaridade mínimas exigidas pela legislação, assim como inadequação dos cursos de formação, em relação às necessidades de formação para Educação Infantil.

Outro estudo, realizado em 2010 pelo Ministério da Educação para avaliar a qualidade da Educação Infantil em 150 centros de Educação Infantil de seis capitais do Brasil, constatou a falta de garantias de condições mínimas de qualidade, sobretudo, relacionadas à formação, qualificação e valorização dos profissionais, o que pode prejudicar as crianças no seu desenvolvimento e desrespeitá-las em seus direitos, indicando que são questões que afetam diretamente a qualidade. Neste estudo, os professores mostraram que estão, até certo ponto, conscientes desses problemas, resultado das políticas adotadas em seus municípios. Porém, afirmam que sozinhos não são capazes de tomar iniciativas para atuar sobre os aspectos negativos apontados pelo estudo (CAMPOS, 2013, p. 36).

A formação e a valorização dos profissionais da Educação Infantil merecem atenção especial do Estado enquanto provedor social das políticas desse setor, dada a relevância de sua atuação na faixa de 0 a 5 anos. Além de formação acadêmica prévia, se requer a formação sistemática e permanente desses profissionais, que inclua o conhecimento das bases científicas do desenvolvimento da criança, do processo ensino aprendizagem, e das práticas de cuidado e educação da criança, bem como abarquem as questões políticas relacionadas 
aos direitos das crianças, sujeitos da Educação Infantil, e dos profissionais envolvidos e responsáveis diretos pelo processo ensino aprendizagem.

Levando em consideração este panorama, refletir sobre a qualidade da Educação Infantil implica pensar sobre os avanços na legislação (na Constituição, 1988, e na LDB, 1996) que determina o direito da criança à educação e melhoria da qualidade do atendimento como seu principal objetivo, e a situação de crise que hoje ainda vivem as instituições de Educação Infantil no Brasil. Implica indagar se as práticas assistencialistas compensatórias foram superadas, se as deficiências em termos de ofertas de vagas, de infraestruturas físicas e materiais, e da formação e qualificação profissional foram resolvidas. Além de indagar se o atendimento destas instituições ainda se caracteriza como pobre para pobre.

Existem enormes lacunas entre o desenvolvimento de um modelo de atendimento pautado nos princípios e dimensões de qualidade propostos pelos documentos legais e pela legislação vigente, inclusive pela própria Política Nacional de Educação Infantil, e aquilo que é mostrado no campo da pesquisa em diferentes estudos, como pelo próprio Ministério da Educação (CAMPOS et al., 2006; BRASIL, 2010; CAMPOS, 2013).

\section{CONSIDERAÇÕES FINAIS}

O governo, através do Ministério da Educação, redigiu os documentos Referencial Curricular Nacional para a Educação Infantil, 1998; Diretrizes Curriculares Nacionais para a Educação Infantil, 1999; Parâmetros Básicos de Infraestrutura para Instituições de Educação Infantil, 2004; Parâmetros Nacionais de Qualidade para Educação Infantil, Volume 1 e 2, 2006; Critérios para um Atendimento em Creches que Respeite os Direitos Fundamentais das Crianças, 2009; e os Indicadores da Qualidade na Educação Infantil, 2009.

Com base nesse aparato legal, a qualidade da Educação Infantil passou a ser considerada condição extremamente importante, especificamente porque tanto os estudos científicos quanto a prática social têm demonstrado estreita ligação entre os níveis de qualidade dos serviços de cuidados e de educação de crianças em instituições de Educação Infantil e o seu desenvolvimento integral e bem-estar. A partir desse entendimento e com o avanço do debate da qualidade da educação, outros elementos vêm sendo agregados ao conceito de qualidade da Educação Infantil, integrando outros aspectos além das demandas físicas, e, numa perspectiva democrática, comprometida com as transformações sociais e a melhoria da qualidade da educação para todos. Soma-se a isso a qualidade como direito de 
cidadania, que deve ser garantida pela e através da implementação de políticas sociais por parte do Estado no seu papel de provedor social, que considere as crianças como sujeito de direito a um atendimento que respeite as suas necessidades e demandas.

Nesses termos, considera-se que o conhecimento e a compreensão do conteúdo desses documentos por parte dos gestores públicos e dos profissionais da Educação Infantil são de fundamental importância para a sua adoção, implementação e resultados, conforme recomenda o Ministério da Educação. Contudo, e contraditoriamente, os resultados deste estudo mostram que, apesar dos Parâmetros Nacionais de Qualidade para Educação Infantil terem sido publicados há cerca de 10 anos, e os Indicadores da Qualidade na Educação Infantil há 7 anos, estes instrumentos ainda não são conhecidos pelos gestores, coordenadores, professores e auxiliares de Educação Infantil, assim como não foram implementados pelas instituições contempladas como lócus da pesquisa e, portanto, não fundamentam a prática social dos profissionais envolvidos com a Educação Infantil.

No contexto das representações sociais das entrevistadas, as instituições de Educação Infantil aparecem sempre em situações precárias, seja quanto à formação de pessoal, à infraestrutura física e material, seja relacionada às condições e relações de trabalho e qualidade de vida das educadoras, dentre outras situações.

No que concerne à carência de conhecimento das profissionais entrevistadas acerca dos diferentes percursos seguidos pelo debate sobre as políticas de avaliação da qualidade da educação, tal fato reflete a importância da relação indissociável entre a formação continuada do educador e a atuação docente. A ação pedagógica só se constituirá em um trabalho de educação de qualidade se o governo, enquanto gestor público das demandas educacionais e responsável pela gestão das instituições de Educação Infantil, estabelecer como prioridade a formação continuada de seus educadores. Para isto, as instituições precisam efetivamente se tornar lócus privilegiado de estudos, pesquisas, atualizações, reflexões coletivas sobre conhecimentos e práticas que tratam da Educação Infantil em seus diversos aspectos, de forma crítica e interdisciplinar.

Limitações generalizadas são identificadas a partir das análises das representações sociais das protagonistas da Educação Infantil acerca do que trata a problemática estudada. Entraves que vão além do não cumprimento da implementação dos Parâmetros Nacionais de Qualidade para Educação Infantil e da utilização dos Indicadores da Qualidade na Educação Infantil como instrumentos de autoavaliação destas instituições. Desconsidera-se a participação da família enquanto contribuinte e usuária de direito dos serviços de consumo coletivo, e o 
direito da criança a um atendimento de qualidade que se efetive na perspectiva do seu desenvolvimento integral.

A análise dessa problemática sugere investigação mais aprofundada, na medida em que as representações sociais dos sujeitos da pesquisa parecem revelar ainda 0 caráter assistencialista compensatório atribuído a essas instituições ao longo de sua história, e que as configuram do modo que ainda hoje o são. Apesar de todo o aparato legal, o padrão de qualidade da Educação Infantil vigente no atendimento à criança é centrado, principalmente, na insuficiência de recursos, na má qualidade do atendimento, na desvalorização e desqualificação do profissional, na ausência de cumprimento da legislação específica que garante o direito da criança a um atendimento de qualidade.

\section{REFERÊNCIAS}

ALVÂNTARA, Anelise Montañes; VESCE, Gabriela Eying Possoli. As representações sociais no discurso do sujeito coletivo no âmbito da pesquisa qualitativa. In: Anais do $8^{\circ}$ Congresso Nacional de Educação. 2008.

BRASIL. Constituição da República Federativa do Brasil: promulgada em 5 de outubro de 1988. Brasília, DF: Senado Federal/Centro Gráfico, 1988.

BRASIL. ECA (1990). Estatuto da Criança e do Adolescente. Lei n.8.069, 13 de Julho de 1990 e legislação correlata (recurso eletrônico) - 9.ed.-Brasilia: - Câmara dos Deputados. Edições Câmara, 2010. 207p.

BRASIL. Lei no 9394 de 20 de dezembro de 1996. Estabelece a Lei de Diretrizes e Bases da Educação Nacional. 1996. Diário Oficial da União. Brasília, DF, 1996.

BRASIL. Ministério da Educação e Cultura. Secretaria de Educação Básica Indicadores da qualidade na Educação Infantil. Brasília: MEC/SEB, 2009. 64p.

BRASIL. Ministério da Educação e do Desporto. Secretaria de Educação Básica. Parâmetros nacionais de qualidade para a educação infantil/Ministério da Educação. Secretaria de Educação Básica - Volume 1, Brasília, 2006.

BRASIL. Ministério da Educação e do Desporto. Secretaria de Educação Básica. Parâmetros nacionais de qualidade para a educação infantil/Ministério da Educação. Secretaria de Educação Básica - Volume 2, Brasília, 2006.

BRASIL. Ministério da Educação e do Desporto. Secretária de Educação Básica. Política Nacional de Educação Infantil: pelo direito das crianças de zero a seis anos à educação. Brasília: MEC/SEF, 2003. 
BRASIL. Ministério da Educação. Secretaria de Educação Continuada, Alfabetização e Diversidade. Diretoria de Políticas de Educação de Jovens e Adultos. Princípios da Educação de Jovens e Adultos. Fundamentos Legais. Brasília: MEC/SEF, 2009.

BRASIL. Ministério da Educação e Cultura /INEP. O desafio de uma educação de qualidade para todos: educação no Brasil - 1990-2000. Brasília, 2006.

BRASIL. Política nacional de Educação Infantil: pelo direito das crianças de zero a seis anos à educação. Brasília: Secretaria de Educação Básica. Ministério da Educação, 2005.

BRASIL. Plano Nacional de Educação. 2001. Acessado em: 27/07/2014. Disponível em http://portal.mec.gov.br/arquivos/pdf/pne.pdf.

BRASIL. Presidência da República - Casa Civil. LEI № 8.069, DE 13 DE JULHO DE 1990. Dispõe sobre o Estatuto da criança e do Adolescente e dá outras providências. Brasília, 1990.

CAMPOS, Maria Malta.; FÜLLGRAF, Jodete; WIGGERS, Verena. Qualidade da Educação Infantil Brasileira: Alguns Resultados de Pesquisa. Cadernos de Pesquia. vol.36, n. 127, p. 87-128 jan./abr. 2006

CAMPOS, Maria Malta; ESPOSITOI, Yara Lúcia; BHERING, Eliana. Avaliação da qualidade da educação infantil. Cad. Pesquisa. vol.41 no.142 São Paulo Jan./Abr. 2011

CAMPOS, Maria Malta. Entre as políticas de qualidade e a qualidade das práticas. Cadernos de Pesquisa. vol.43, n.148, p.22-43 jan./abr. 2013

CARREIRA, Denise; PINTO, José Marcelino Rezende. Custo Aluno - Qualidade Inicial: rumo à educação pública de qualidade no Brasil. São Paulo: Global: Campanha Nacional pelo Direito a Educação, 2007.

CORTELLA, Mário Sergio. Prefácio: Qualificar a qualidade, desqualificar a complacência. In: CARREIRA, Denise; PINTO, José Marcelino Resende. Custo Aluno - Qualidade Inicial: rumo à educação pública de qualidade no Brasil. São Paulo: Global: Campanha Nacional pelo Direito a Educação, 2007.

DAVOK, Delsi Fries. Qualidade em educação. Avaliação. Campinas; Sorocaba, v. 12, n. 3, p. 505-513, set. São Paulo, 2007.

DOWBOR, Ladislaw. Reflexões Atuais Sobre Cidades, Família e Escola: Impactos na vida das Crianças e do planeta. In: FONTENELLE, Laís; HENRIQUES, Isabella. Criança e Consumo 10 Anos de Transformação. Instituto Alana, 1 ed., são Paulo, 2016.

DEMO, Pedro. Educação e qualidade. 10. ed. Campinas, SP: Papirus, 2006.

GENTILI, Pablo; SILVA, Tomaz Tadeu. Neoliberalismo, qualidade total e educação: visões críticas. 2 ed. Petrópolis, 2015.

GRAMSCI, Antônio. Intelectuais e a Organização da Cultura. São Paulo: Civilização Brasileira, 1989. 
HADDAD, Lenira. Política de Pré-Escola e Creches no País. In: CONGRESSO BRASILEIRO DE ECONOMIA DOMÉSTICA. 10. Anais. Piracicaba-SP, 1989. 83 p.

LOJKINE, Jean. O Estado Capitalista e a Questão Urbana. São Paulo, Martins Fonte, 1981/ 1997. $337 \mathrm{p}$.

LIMA, Ana Maria Campello. Formação do trabalhador de creche. In. I Seminário Estadual: CRECHE UM DIREITO DA FAMÍLIA TRABALHADORA, UM DEVER DO ESTADO E DA SOCIEDADE, 1. Recife: Secretaria de Educação, Cultura e Esportes do Estado de Pernambuco, 1990. 76 p.

LIMA, Wanessa Maria de. Qualidade na educação infantil no Recife como meio de consumo coletivo: discursos e práticas. Dissertação (Mestrado). Programa de Pós-Graduação em Consumo, Cotidiano e Desenvolvimento Social (área de concentração Desenvolvimento Humano), Universidade Federal Rural de Pernambuco, Recife, 2016.

LIMA, Wanessa Maria de; SARAIVA, Joseana Maria. Contexto sócio histórico de construção dos conceitos de qualidade e qualidade da educação: da perspectiva empresarial a educacional como direito de todos. Revista de Administração Educacional, Recife, V. 1 . № 1 . 2017 jan./jun. 2017 p.52-66

MOSCOVICI. Serge. Representações sociais: investigações em psicologia social. Rio de Janeiro, Vozes, 2003. 404 p.

MOSS, Paulo. Para além do problema com qualidade. In: MACHADO, Maria Lúcia de A. (Ed.). Encontros e desencontros em educação infantil. São Paulo: Cortez, 2002. p. 17-25.

NRODOWSKI, Mariano. Comenius e a Educação Tradução: Alfredo Veiga Neto. Belo Horizonte 2001. PREFEITURA DO RECIFE. Plano Plurianual para o período de 2014/2017. Recife, Outubro, 2013.

PEREIRA, Jaquelline de Andrade. Acessibilidade para pessoas com deficiência física e/ou sensorial à hotelaria: na perspectiva do consumo coletivo. 2016. 180 f. Dissertação (Mestrado em Consumo, Cotidiano e Desenvolvimento Pessoal) - Universidade Federal Rural de Pernambuco. Recife - PE, 2016

RICHARDSON, Roberto Jarry. Pesquisa Social: métodos e técnicas. São Paulo: Atlas, 2009.

SARAIVA, Joseana Maria. Perfil do Trabalhador do setor de Nutrição e Saúde de Creches Públicas da Cidade do Recife - PE. Dissertação (Mestrado). Programa de Pós-Graduação em Nutrição (área de concentração Saúde Pública), Universidade Federal de Pernambuco, Recife, 1999.

SARAIVA, Joseana Maria. A lógica do capital e do Estado na provisão dos meios de consumo coletivo. Uma experiência de responsabilidade social no campo da assistência à criança. Recife: Editora UFPE, 2015. 
SIQUEIRA, Erlane Bandeira de Melo. As representações sociais das práticas dos Conselheiros Tutelares: o caso do Conselho Tutelar da Zona Norte de João Pessoa. Tese (Doutorado). Programa de Pós-Graduação em Serviço Social, Universidade Federal de Pernambuco. CCSA. Serviço Social, 2009.

UNICEF. Fundo das Nações Unidas para a Infância. Relatório Situação Mundial da Infância, UNICEF, Nova lorque, 2008.

https://www.unicef.org/publications/files/SOWC_2015_Summary_Portuguese_Web.pdf

UNICEF. Fundo das Nações Unidas para a Infância. Mal necessário: creches no Departamento Nacional da Criança (1940-1970). Caderno de Pesquisa, São Paulo, v. 10, n. 67, p. 3-16, 1987 OU, 1988.

YIN, Robert. K. Estudo de caso: planejamento e método. 3. ed. Porto Alegre: Bookman, 2001. ZABALZA, Miguel. Qualidade em Educação Infantil. Porto Alegre: Artmed, 1998. 